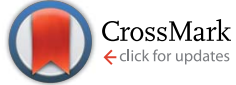

Cite this: J. Mater. Chem. A, 2016, 4, 11611

Received 23rd May 2016

Accepted 27th June 2016

DOI: $10.1039 / c 6 t a 04289 a$

www.rsc.org/MaterialsA

\section{Electrochemical oxidation to construct a nickel sulfide/oxide heterostructure with improvement of capacitance $\uparrow$}

\author{
Xuan Liu, Bo You, Xin-Yao Yu, Jeffrey Chipman and Yujie Sun*
}

Supercapacitors have been widely recognized as a promising device for the storage of renewable energy. Herein, a facile electrochemical oxidation strategy is described to construct a nickel sulfide/oxide heterostructure which enhances the specific areal capacitance of $\mathrm{Ni}_{3} \mathrm{~S}_{2}$ electrodeposited on nickel foam. The resulting heterostructure electrode exhibits high areal capacitance, 65 times that of the asprepared $\mathrm{Ni}_{3} \mathrm{~S}_{2}$ electrode $\left(2035 \mathrm{mF} \mathrm{cm}^{-2}\right.$ vs. $31 \mathrm{mF} \mathrm{cm}^{-2}$ at a current density of $8 \mathrm{~mA} \mathrm{~cm}^{-2}$ ), while still maintaining great stability, showing no performance degradation after 5000 charge-discharge cycles. Its exceptional capacitance, advanced rate capability, and superior cycling stability are attributed to the transformed composition and unique nanostructure achieved during electrochemical oxidation, which can provide a large electrochemically active surface area, fast electron/electrolyte ion transport, and robust structural stability. Such a low-cost and facile strategy can be potentially applicable to prepare many other materials for supercapacitor applications.

Because of the increasing energy demand and depleting fossil fuels worldwide, a great deal of effort has been invested in developing novel materials for advanced energy storage devices, ${ }^{1-3}$ among which supercapacitors have attracted considerable attention because of their low cost, long cycling life, and high power density. ${ }^{4-7}$ Generally, two types of supercapacitors have been widely studied: electrochemical doublelayer capacitors and pseudocapacitors. Benefiting from the fast and reversible surface redox reactions for charge storage, pseudocapacitors usually possess much higher energy density than electrochemical double-layer capacitors.

Taking into account the decisive role of electrode materials for supercapacitors, many researchers have focused on the rational design and synthesis of nonprecious, stable, and highperformance electrode materials for supercapacitor applications. Particularly, transition metal sulfides/oxides have

Department of Chemistry and Biochemistry, Utah State University, Logan, Utah 84322, USA. E-mail:yujie.sun@usu.edu

$\dagger$ Electronic supplementary information (ESI) available. See DOI: 10.1039/c6ta04289a attracted intense interest due to their high theoretical capacitance, environmental compatibility, low cost, and earth abundance. ${ }^{8-13}$ In general, there are two primary approaches to obtain pseudocapacitors with high performance. The first strategy is to optimize the electrode materials by varying the composition, such as mono- and heterometallic oxides and chalcogenides (e.g., $\mathrm{NiS},{ }^{14} \mathrm{NiO},{ }^{15} \mathrm{Ni}_{3} \mathrm{~S}_{2},{ }^{16} \mathrm{Co}_{9} \mathrm{~S}_{8},{ }^{17} \quad \mathrm{Co}_{3} \mathrm{O}_{4}{ }^{18}$ $\mathrm{NiCo}_{2} \mathrm{O}_{4},{ }^{19} \mathrm{CoNi}_{2} \mathrm{~S}_{4},{ }^{20}$ and $\mathrm{NiCo}_{2} \mathrm{~S}_{4}{ }^{21}$ ), which have been reported to have excellent capacitance. Another widely adopted approach is to tailor the structure of the electrode materials via nanoengineering to result in a high surface area. Following this strategy, many nanostructured materials, for instance electrode materials of hollow prisms, nanospheres, and nanowires, have been reported with improved capacitance relative to their corresponding bulk counterparts. ${ }^{22-24}$ Despite significant progress, designing a low-cost and facile process for fabricating highperformance supercapacitor electrodes is still challenging but highly desirable.

Herein, we describe an alternative in situ electrochemical oxidation (denoted as ECO) approach to construct a nickel sulfide/oxide heterostructure which enhances the specific areal capacitance of the $\mathrm{Ni}_{3} \mathrm{~S}_{2} /$ nickel foam $\left(\mathrm{Ni}_{3} \mathrm{~S}_{2} / \mathrm{NF}\right)$ electrode. The resulting ECO- $\mathrm{Ni}_{3} \mathrm{~S}_{2} / \mathrm{NF}$ exhibits a remarkably increased areal capacitance of $2035 \mathrm{mF} \mathrm{cm} \mathrm{cm}^{-2}$, which is 65 times that of the parent $\mathrm{Ni}_{3} \mathrm{~S}_{2} / \mathrm{NF}$ at a current density of $8 \mathrm{~mA} \mathrm{~cm}{ }^{-2}$. Furthermore, the ECO-Ni $\mathrm{S}_{2} / \mathrm{NF}$ also displays excellent cycling stability, retaining the initial specific capacitance even after 5000 chargedischarge cycles. Such an effective strategy is potentially applicable to produce many other electrode materials for multiple energy-related applications.

Potentiodynamic deposition was utilized to prepare $\mathrm{Ni}_{3} \mathrm{~S}_{2}$ on nickel foam (see the ESI $\dagger$ for details). ${ }^{25-27}$ In sharp contrast to the smooth morphology of a pristine nickel foam (Fig. S1 $\dagger$ ), the entire surface of $\mathrm{Ni}_{3} \mathrm{~S}_{2} / \mathrm{NF}$ was fully covered by nanoflake-like composites with no regular crystalline particles or aggregates (Fig. 1a and S2a $\dagger$ ). Elemental mapping results of $\mathrm{Ni}_{3} \mathrm{~S}_{2} / \mathrm{NF}$ (Fig. S2 $\mathrm{b} \dagger$ ) confirmed the uniform coverage of the entire nickel foam with evenly distributed nickel and sulfur. The X-ray 


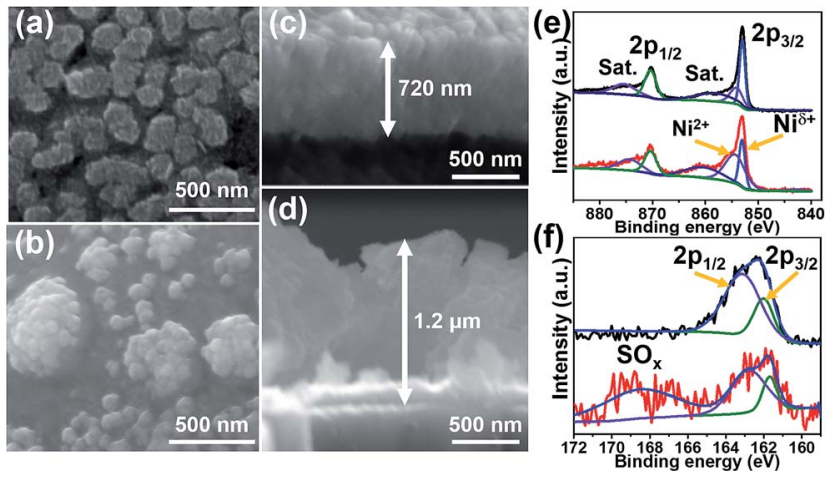

Fig. 1 (a and c) SEM and cross-section SEM images of $\mathrm{Ni}_{3} \mathrm{~S}_{2} / \mathrm{NF}$ and $(\mathrm{b}$ and d) SEM and cross-section SEM images of ECO-Ni $\mathrm{S}_{2} / \mathrm{NF}$; highresolution $\mathrm{Ni} 2 \mathrm{p}(\mathrm{e})$ and $\mathrm{S} 2 \mathrm{p}(\mathrm{f})$ spectra of $\mathrm{Ni}_{3} \mathrm{~S}_{2} / \mathrm{NF}$ (blue) and ECO$\mathrm{Ni}_{3} \mathrm{~S}_{2} / \mathrm{NF}$ (red).

diffraction (XRD) pattern of $\mathrm{Ni}_{3} \mathrm{~S}_{2} / \mathrm{NF}$ (Fig. S3 $\dagger$ ) showed strong peaks at $45.2^{\circ}, 52.8^{\circ}$, and $77.2^{\circ}$, which could be assigned to the crystalline (111), (200), and (220) facets of the nickel foam, respectively. Additionally, weak but well distinguished peaks at $22.1^{\circ}, 31.5^{\circ}, 37.7^{\circ}, 50.2^{\circ}$, and $55.1^{\circ}$ were also observed, matching the standard XRD pattern of $\mathrm{Ni}_{3} \mathrm{~S}_{2}$ (PDF: 44-1418), in good agreement with the published results of electrodeposited $\mathrm{Ni}_{3} \mathrm{~S}_{2}$ films on fluorine-doped tin oxide electrodes. ${ }^{28}$

The ECO- $\mathrm{Ni}_{3} \mathrm{~S}_{2} / \mathrm{NF}$ was prepared via potential dynamic cycling of $\mathrm{Ni}_{3} \mathrm{~S}_{2} / \mathrm{NF}$ between 0.6 and $1.2 \mathrm{~V} v s$. $\mathrm{Ag} / \mathrm{AgCl}$ in $1.0 \mathrm{M}$ $\mathrm{KOH}$ for several scans until stable CV curves were obtained (Fig. S4 $\dagger$ ). The overall structure of the resulting ECO- $\mathrm{Ni}_{3} \mathrm{~S}_{2} / \mathrm{NF}$ remained the same as that of $\mathrm{Ni}_{3} \mathrm{~S}_{2} / \mathrm{NF}$ (Fig. S5a $\uparrow$ ). However, a close inspection reveals the presence of a large amount of wrinkled nanospheres (Fig. 1b). Unlike the nanoflakes of $\mathrm{Ni}_{3} \mathrm{~S}_{2} /$ $\mathrm{NF}$, these wrinkled nanospheres were attached to the surface of nickel foam tightly and seamlessly, which might be beneficial for fast electron/electrolyte ion transport and robust stability. The elemental mapping images (Fig. $\mathrm{S} 5 \mathrm{~b} \dagger$ ) of ECO- $\mathrm{Ni}_{3} \mathrm{~S}_{2} / \mathrm{NF}$ demonstrated that both nickel and sulfur were still distributed uniformly over the entire electrode, wherein a large amount of oxygen was also observed. During the electrochemical oxidation process, the working electrode $\left(\mathrm{Ni}_{3} \mathrm{~S}_{2} / \mathrm{NF}\right)$ also performed the $\mathrm{O}_{2}$ evolution reaction. $\mathrm{O}_{2}$ evolution played a crucial role in the formation of a porous structure since the $\mathrm{O}_{2}$ bubbles derived from the anode created continuous pathways from the surface of $\mathrm{Ni}_{3} \mathrm{~S}_{2}$ to the electrolyte. $\mathrm{O}_{2}$ evolution could produce many extra pores in the material which were accessible to the electrolyte. Thus, electrochemical oxidation can not only produce a porous structure but also expose more electrochemically active sites. ${ }^{29,30}$ In order to probe the inner structure of $\mathrm{Ni}_{3} \mathrm{~S}_{2} / \mathrm{NF}$ and ECO-Ni $\mathrm{N}_{3} \mathrm{~S}_{2} / \mathrm{NF}$, cross-section SEM images of both electrodes were collected. Fig. 1c shows an even and intense layer of $\mathrm{Ni}_{3} \mathrm{~S}_{2}$ in $\mathrm{Ni}_{3} \mathrm{~S}_{2} / \mathrm{NF}$ with a thickness of around $720 \mathrm{~nm}$. After ECO, the deposited layer became much rougher and the thickness increased from $\sim 720 \mathrm{~nm}$ to $1.2 \mu \mathrm{m}$ (Fig. 1d). Despite the porous surface, a thin and intense layer of $\mathrm{Ni}_{3} \mathrm{~S}_{2}$ still existed in close contact with the nickel foam. The elemental mapping images of ECO-Ni ${ }_{3} \mathrm{~S}_{2} / \mathrm{NF}$ (Fig. S6 $\dagger$ ) showed that the $\mathrm{S}$ content in the inner layer was much higher than that in the outer layer, further confirming the formation of a nickel sulfide/oxide heterostructure on the surface during ECO. The XRD pattern of ECO$\mathrm{Ni}_{3} \mathrm{~S}_{2} / \mathrm{NF}$ was very similar to that of $\mathrm{Ni}_{3} \mathrm{~S}_{2} / \mathrm{NF}$, indicating the remaining $\mathrm{Ni}_{3} \mathrm{~S}_{2}$ after ECO (Fig. S3†). The lack of peaks attributable to nickel oxides was probably due to the amorphous nature of the newly formed oxides. Inductively coupled plasma atomic emission spectroscopy analysis of $\mathrm{Ni}_{3} \mathrm{~S}_{2} / \mathrm{NF}$ showed the deposited amount of $\mathrm{Ni}$ and $\mathrm{S}$ to be 4.62 and $1.68 \mathrm{mg} \mathrm{cm}^{-2}$, respectively. After ECO, the $\mathrm{S}$ content decreased to $0.56 \mathrm{mg}$ $\mathrm{cm}^{-2}$, implying that nearly two thirds of the original $\mathrm{Ni}_{3} \mathrm{~S}_{2}$ were oxidized during ECO.

In order to further probe the composition and valence state of each element in the electrodeposited samples, X-ray photoelectron spectroscopy (XPS) was conducted. The XPS survey spectra of $\mathrm{Ni}_{3} \mathrm{~S}_{2} / \mathrm{NF}$ and ECO-Ni $\mathrm{N}_{3} / \mathrm{NF}$ are included in Fig. $\mathrm{S} 7, \dagger$ displaying all the anticipated elements like $\mathrm{Ni}$ and $\mathrm{S}$. The much higher intensity of the $\mathrm{O} 1 \mathrm{~s}$ peak at $528 \mathrm{eV}$ of $\mathrm{ECO}-\mathrm{Ni}_{3} \mathrm{~S}_{2} / \mathrm{NF}$ compared to that of $\mathrm{Ni}_{3} \mathrm{~S}_{2} / \mathrm{NF}$ demonstrated the large degree of surface oxidation of the former during ECO (Fig. S7b $\dagger$ ), ${ }^{31,32}$ in agreement with the above elemental mapping results (Fig. S5 †). The high-resolution Ni and S XPS spectra of these two samples are compared in Fig. 1e and f. Ni 2p spectra of both samples could be deconvoluted into two spin-orbital doublets, which were assigned to $\mathrm{Ni} 2 \mathrm{p}_{3 / 2}$ and $2 \mathrm{p}_{1 / 2}$, and two shakeup satellites (Fig. 1e). ${ }^{19,33,34}$ The high-resolution $\mathrm{Ni} 2 \mathrm{p}_{3 / 2}$ spectrum was deconvoluted into three subpeaks at binding energies of 852.8, 854.6, and $860.9 \mathrm{eV}$ (Fig. 1e), assignable to $\mathrm{Ni}^{\delta+}$ in $\mathrm{Ni}_{3} \mathrm{~S}_{2}$, oxidized $\mathrm{Ni}$ species, and the $\mathrm{Ni} 2 \mathrm{p}_{3 / 2}$ satellite peak of $\mathrm{Ni}_{3} \mathrm{~S}_{2}$, respectively. Similarly, XPS fitting of the high-resolution S 2p spectra (Fig. 1f) resulted in a doublet at 161.8 and $163.2 \mathrm{eV}$, corresponding to $S 2 p_{3 / 2}$ and $2 p_{1 / 2}$ peaks, respectively. ${ }^{35}$ The remaining sulfide peak from $\mathrm{Ni}_{3} \mathrm{~S}_{2}$ in the $\mathrm{S} 2 \mathrm{p}$ spectrum of ECO$\mathrm{Ni}_{3} \mathrm{~S}_{2} / \mathrm{NF}$ corroborated the partial oxidation of $\mathrm{Ni}_{3} \mathrm{~S}_{2}$ during the anodic potential cycling.

The electrochemical properties of $\mathrm{Ni}_{3} \mathrm{~S}_{2} / \mathrm{NF}$ and ECO- $\mathrm{Ni}_{3} \mathrm{~S}_{2} /$ $\mathrm{NF}$ were investigated in a three-electrode configuration (see the $\mathrm{ESI} \dagger$ for details). We first varied the numbers of potentiodynamic deposition cycling to optimize the capacitance performance of $\mathrm{Ni}_{3} \mathrm{~S}_{2} / \mathrm{NF}$ and the corresponding ECO-Ni $\mathrm{S}_{2} / \mathrm{NF}$. As shown in Fig. S8, $\uparrow$ the best energy storage properties were achieved at 15 potential cycles. Hereafter, all the electrochemical studies were conducted under the optimal conditions unless noted otherwise. In virtue of electrodeposition, no conductive agents/binders were needed for the electrochemical studies. The cyclic voltammograms of $\mathrm{Ni}_{3} \mathrm{~S}_{2} / \mathrm{NF}$ and ECO-Ni $\mathrm{N}_{3} \mathrm{~S}_{2} /$ $\mathrm{NF}$ collected between 0 and $0.55 \mathrm{~V} v s$. $\mathrm{Ag} / \mathrm{AgCl}$ are shown in Fig. 2a. It clearly shows that ECO- $\mathrm{Ni}_{3} \mathrm{~S}_{2} / \mathrm{NF}$ displays an apparent redox feature with anodic and cathodic peaks at 0.41 and $0.24 \mathrm{~V}$ $v s$. $\mathrm{Ag} / \mathrm{AgCl}$, respectively. The integrated area of the anodic peak is nearly equal to that of the cathodic peak, implying a good reversibility of the fast charge-discharge process of ECO- $\mathrm{Ni}_{3} \mathrm{~S}_{2} /$ $\mathrm{NF} .^{36}$ On the same scale of current density, it is difficult to define the redox features of $\mathrm{Ni}_{3} \mathrm{~S}_{2} / \mathrm{NF}$. The inset in Fig. 2a displays an expanded current region to well present the redox peaks of $\mathrm{Ni}_{3} \mathrm{~S}_{2} / \mathrm{NF}$, which exhibits anodic and cathodic peaks at 0.37 and $0.31 \mathrm{~V} v$ s. $\mathrm{Ag} / \mathrm{AgCl}$. Both of the redox features of ECO- 

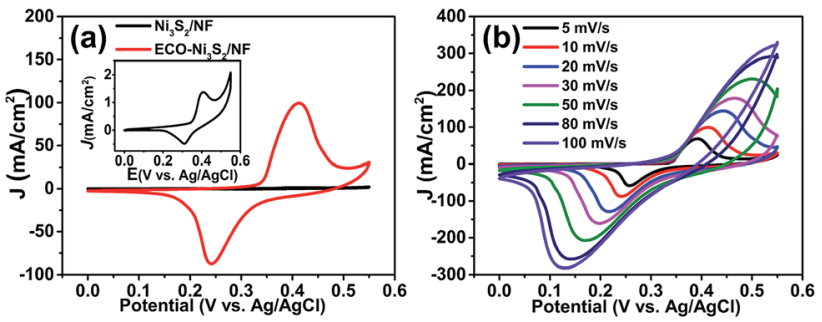

Fig. 2 (a) Cyclic voltammograms of $\mathrm{Ni}_{3} \mathrm{~S}_{2} / \mathrm{NF}$ (black and inset) and $\mathrm{ECO}-\mathrm{Ni}_{3} \mathrm{~S}_{2} / \mathrm{NF}$ (red) at a scan rate of $10 \mathrm{mV} \mathrm{s}^{-1}$ in $1.0 \mathrm{M} \mathrm{KOH}$. (b) Cyclic voltammograms of ECO $-\mathrm{Ni}_{3} \mathrm{~S}_{2} / \mathrm{NF}$ at scan rates of 5 to $100 \mathrm{mV} \mathrm{s}^{-1}$.

$\mathrm{Ni}_{3} \mathrm{~S}_{2} / \mathrm{NF}$ and $\mathrm{Ni}_{3} \mathrm{~S}_{2} / \mathrm{NF}$ correspond to faradaic process-based pseudocapacitance ${ }^{37}$ and the former apparently demonstrates a much higher capacitance than the latter. In addition, the redox features of $\mathrm{ECO}-\mathrm{Ni}_{3} \mathrm{~S}_{2} / \mathrm{NF}$ were further examined in Fig. $2 \mathrm{~b}$ with increasing scan rate from 5 to $100 \mathrm{mV} \mathrm{s}^{-1}$. With the increase in scan rate, the well-defined redox peaks were still maintained while the respective current density increased accordingly. A similar trend was observed for $\mathrm{Ni}_{3} \mathrm{~S}_{2} / \mathrm{NF}$ (Fig. S9†). At higher scan rates, the anodic peak shifted positively while the cathodic peak moved to lower potential, likely due to the increasing voltage drop with increasing scan rates.

Next, the galvanostatic charge-discharge (GCD) measurements were carried out to confirm the improvement of capacitance after electrochemical oxidation. The areal capacitance of an electrode can be calculated from the GCD curve based on the equation $C=\frac{I \Delta t}{A \Delta V}$, where $C$ is the areal capacitance, $I$ is the discharge current, $\Delta t$ is the discharge time, $A$ is the electrode
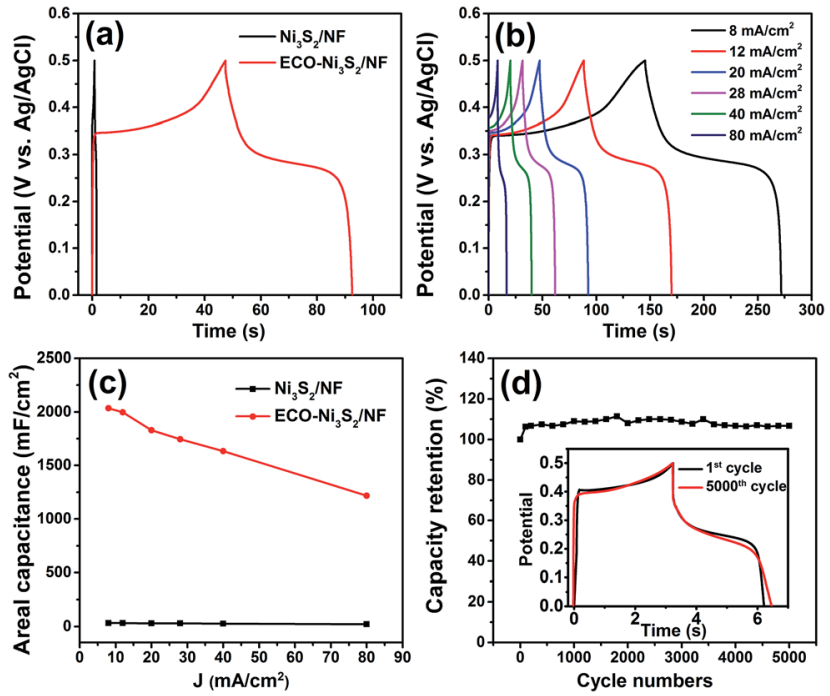

Fig. 3 (a) Galvanostatic charge-discharge curves of the $\mathrm{Ni}_{3} \mathrm{~S}_{2} / \mathrm{NF}$ (black) and $\mathrm{ECO}-\mathrm{Ni}_{3} \mathrm{~S}_{2} / \mathrm{NF}$ (red) at a current density of $20 \mathrm{~mA} \mathrm{~cm}{ }^{-2}$ in $1.0 \mathrm{M} \mathrm{KOH}$. (b) Galvanostatic charge-discharge curves of the ECO$\mathrm{Ni}_{3} \mathrm{~S}_{2} / \mathrm{NF}$ at various current densities. (c) The variation of area capacitances with different current densities for the $\mathrm{Ni}_{3} \mathrm{~S}_{2} / \mathrm{NF}$ (black) and $\mathrm{ECO}-\mathrm{Ni}_{3} \mathrm{~S}_{2} / \mathrm{NF}$ (red). (d) Stability of the ECO $-\mathrm{Ni}_{3} \mathrm{~S}_{2} / \mathrm{NF}$ for 5000 cycles. The inset shows the galvanostatic charge-discharge curves of the $\mathrm{ECO}-\mathrm{Ni}_{3} \mathrm{~S}_{2} / \mathrm{NF}$ of the first cycle and the $5000^{\text {th }}$ cycle at a current density of $100 \mathrm{~mA} \mathrm{~cm}^{-2}$. area and $\Delta V$ is the potential window. Fig. 3a shows the GCD curves of $\mathrm{Ni}_{3} \mathrm{~S}_{2} / \mathrm{NF}$ and ECO- $\mathrm{Ni}_{3} \mathrm{~S}_{2} / \mathrm{NF}$ at a current density of $20 \mathrm{~mA} \mathrm{~cm}{ }^{-2}$, wherein ECO- $\mathrm{Ni}_{3} \mathrm{~S}_{2} / \mathrm{NF}$ exhibits a much longer discharge time. In fact, the calculated capacitance of ECO-Ni $\mathrm{N}_{3} /$ $\mathrm{NF}\left(1828 \mathrm{mF} \mathrm{cm}^{-2}\right)$ is 62 times that of $\mathrm{Ni}_{3} \mathrm{~S}_{2} / \mathrm{NF}\left(29.6 \mathrm{mF} \mathrm{cm}^{-2}\right)$. Fig. $3 \mathrm{~b}$ shows the GCD curves at varying current densities of 8 , $12,20,28,40$, and $80 \mathrm{mV} \mathrm{cm}^{-2}$. The resulting areal capacitances of ECO- $\mathrm{Ni}_{3} \mathrm{~S}_{2} / \mathrm{NF}$ were 2035, 1996, 1828, 1744, 1635, and 1216 $\mathrm{mF} \mathrm{cm}^{-2}$, all substantially larger than those of the pristine $\mathrm{Ni}_{3} \mathrm{~S}_{2} / \mathrm{NF}$ (Fig. S10†). Although with increasing current density, a decrease in capacitance was observed for ECO- $\mathrm{Ni}_{3} \mathrm{~S}_{2} / \mathrm{NF}$, it still retained more than $1200 \mathrm{mF} \mathrm{cm}^{-2}$ even at $80 \mathrm{~mA} \mathrm{~cm}^{-2}$ (Fig. 3c). In fact, over the entire range of current density ( 8 to $80 \mathrm{~mA}$ $\mathrm{cm}^{-2}$ ), the areal capacitance of ECO- $\mathrm{Ni}_{3} \mathrm{~S}_{2} / \mathrm{NF}$ remained at least 60 times higher than that of $\mathrm{Ni}_{3} \mathrm{~S}_{2} / \mathrm{NF}$ (Table S1 $\dagger$ ). It should be noted that the possible capacitance contribution from the oxidized nickel foam substrate was negligible (Fig. S11†). Besides the improvement of capacitance of $\mathrm{ECO}-\mathrm{Ni}_{3} \mathrm{~S}_{2} / \mathrm{NF}$ compared to that of the parent $\mathrm{Ni}_{3} \mathrm{~S}_{2} / \mathrm{NF}$, the unique heterostructure of ECO- $\mathrm{Ni}_{3} \mathrm{~S}_{2} / \mathrm{NF}$ has superior capacitance to many other nickel sulfides and nickel oxides. ${ }^{20,38,39}$ More detailed comparison is listed in Table S2. $\dagger$ The coulombic efficiencies of $\mathrm{Ni}_{3} \mathrm{~S}_{2} / \mathrm{NF}$ and ECO- $\mathrm{Ni}_{3} \mathrm{~S}_{2} / \mathrm{NF}$ at different current densities are shown in Fig. S12. $\dagger$ With the increase in current density, the coulombic efficiencies of both ECO- $\mathrm{Ni}_{3} \mathrm{~S}_{2} / \mathrm{NF}$ and $\mathrm{Ni}_{3} \mathrm{~S}_{2} / \mathrm{NF}$ increased; however ECO- $\mathrm{Ni}_{3} \mathrm{~S}_{2} / \mathrm{NF}$ possessed an apparently higher coulombic efficiency than $\mathrm{Ni}_{3} \mathrm{~S}_{2} / \mathrm{NF}$ at the same current density, indicating the excellent charge-discharge ability.

Encouraged by the high areal capacitance of ECO- $\mathrm{Ni}_{3} \mathrm{~S}_{2} / \mathrm{NF}$, subsequently we assessed its robustness via consecutive charge-discharge cycles. Fig. 3d shows its areal capacitance retention over 5000 cycles at a current density of $100 \mathrm{~mA} \mathrm{~m}^{-2}$. Apparently, a very stable areal capacitance was maintained throughout the 5000 cycles. The nearly perfect overmatch of the initial GCD curve with the final one (Fig. 3d inset) clearly highlights the superior stability of $E C O-\mathrm{Ni}_{3} \mathrm{~S}_{2} / \mathrm{NF}$ as a supercapacitor.

It is generally accepted that electrochemically active surface area (ECSA) is proportional to double layer capacitance measured in a non-faradaic region. ${ }^{28}$ In order to shed some light on the factors responsible for the capacitance enhancement of
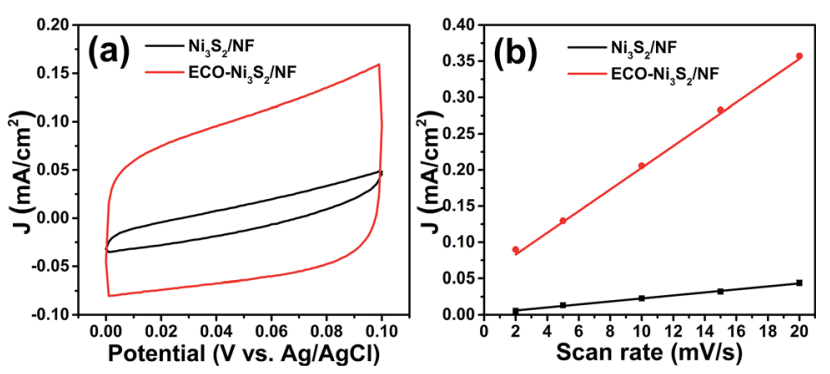

Fig. 4 (a) Cyclic voltammograms of $\mathrm{Ni}_{3} \mathrm{~S}_{2} / \mathrm{NF}$ (black and inset) and $\mathrm{ECO}-\mathrm{Ni}_{3} \mathrm{~S}_{2} / \mathrm{NF}$ (red) at a scan rate of $5 \mathrm{mV} \mathrm{s}^{-1}$ in $1.0 \mathrm{M} \mathrm{KOH}$. (b) The current densities of $\mathrm{Ni}_{3} \mathrm{~S}_{2} / \mathrm{NF}$ (black and inset) and $\mathrm{ECO}-\mathrm{Ni}_{3} \mathrm{~S}_{2} / \mathrm{NF}$ (red) at $0.05 \mathrm{~V} v \mathrm{vs}$. $\mathrm{Ag} / \mathrm{AgCl}$ with respect to varying scan rates from 2 to 20 $\mathrm{mV} \mathrm{s}^{-1}$ 
ECO-Ni ${ }_{3} \mathrm{~S}_{2} / \mathrm{NF}$ compared to that of $\mathrm{Ni}_{3} \mathrm{~S}_{2} / \mathrm{NF}$, we collected their cyclic voltammograms between 0 and $0.1 \mathrm{~V} v$ s. $\mathrm{Ag} / \mathrm{AgCl}$ at varying scan rates (Fig. S13 $\dagger$ ). Fig. 4a compares the cyclic voltammograms of ECO- $\mathrm{Ni}_{3} \mathrm{~S}_{2} / \mathrm{NF}$ and $\mathrm{Ni}_{3} \mathrm{~S}_{2} / \mathrm{NF}$ collected at $5 \mathrm{mV} \mathrm{s}{ }^{-1}$, wherein the former exhibited significantly larger current densities. The linear fitting of the current density at $0.05 \mathrm{~V} v s$. $\mathrm{Ag} / \mathrm{AgCl}$ over the scan rate resulted in an ECSA of ECO-Ni $\mathrm{S}_{3} \mathrm{~S}_{2} / \mathrm{NF} \sim 7$ times that of $\mathrm{Ni}_{3} \mathrm{~S}_{2} / \mathrm{NF}$ (Fig. $4 \mathrm{~b}$ ), probably due to the increased roughness after ECO. Such a high ECSA of ECO- $\mathrm{Ni}_{3} \mathrm{~S}_{2} / \mathrm{NF}$ will be undoubtedly beneficial towards its large capacitance, even though the 60 times higher capacitance of $\mathrm{ECO}-\mathrm{Ni}_{3} \mathrm{~S}_{2} / \mathrm{NF}$ relative to that of $\mathrm{Ni}_{3} \mathrm{~S}_{2} / \mathrm{NF}$ cannot be solely explained by the 7 times increase in the ECSA. We reasoned that the altered composition of the electrode material after electrochemical oxidation (nickel sulfide/oxide heterostructure) would also play an important role in contributing to the resulting high capacitance.

In summary, we reported that a facile electrochemical oxidation strategy was able to construct a nickel sulfide/oxide heterostructure which significantly enhances the areal capacitance of electrodeposited $\mathrm{Ni}_{3} \mathrm{~S}_{2}$ on nickel foam. The resulting heterostructure electrode exhibited an areal capacitance 65 times that of the original $\mathrm{Ni}_{3} \mathrm{~S}_{2} / \mathrm{NF}\left(2035\right.$ vs. $31 \mathrm{mF} \mathrm{cm} \mathrm{cm}^{-2}$ at a current density of $8 \mathrm{~mA} \mathrm{~cm} \mathrm{~cm}^{-2}$ ) and also maintained great stability for 5000 charge-discharge cycles. Such an improved capacitance was likely attributed to the combined effects of the increased electrochemically active surface area and unique heterostructure. Such an electrochemical activation method is complementary to traditional structural engineering and constituent modulation through synthetic routes and hence it is potentially applicable to prepare various electroactive materials for supercapacitor applications.

\section{Conflict of interest}

The authors declare no competing financial interests.

\section{Acknowledgements}

This work was supported by Utah State University. We acknowledge the assistance from the Microscopy Core Facility of Utah State University for the SEM and elemental mapping studies. J. C. was supported by the URCO program of Utah State University.

\section{References}

1 N. S. Choi, Z. Chen, S. A. Freunberger, X. Ji, Y. Sun, K. Amine, G. Yushin, L. F. Nazar, J. Cho and P. G. Bruce, Angew. Chem., Int. Ed., 2012, 51, 9994.

2 J. Jiang, Y. Li, J. Liu, X. Huang, C. Yuan and X. W. Lou, Adv. Mater., 2012, 24, 5166.

3 A. S. Aricò, P. Bruce, B. Scrosati, J. M. Tarascon and W. V. Schalkwijk, Nat. Mater., 2005, 4, 366.

4 G. Wang, L. Zhang and J. Zhang, Chem. Soc. Rev., 2012, 41, 797.

5 B. L. Ellis, P. Knauth and T. Djenizian, Adv. Mater., 2014, 26, 3368.
6 Y. Zhang, Y. Wang, T. Cheng, W. Y. Lai, H. Pang and W. Huang, Chem. Soc. Rev., 2015, 44, 5181.

7 J. Zhang, G. Chen, Q. Zhang, F. Kang and B. You, ACS Appl. Mater. Interfaces, 2015, 7, 12760.

8 B. You and Y. Sun, Adv. Energy Mater., 2016, 6, 1502333.

9 W. Chen, H. Wang, Y. Li, Y. Liu, J. Sun, S. Lee, J.-S. Lee and Y. Cui, ACS Cent. Sci., 2015, 1, 244.

10 L. Zhang, L. Zhou, H. Wu, R. Xu and X. W. Lou, Angew. Chem., Int. Ed., 2012, 51, 7267.

11 M. Huynh, C. Shi, S. J. L. Billinge and D. G. Nocera, J. Am. Chem. Soc., 2015, 137, 14887.

12 Y. Sun, C. Liu, D. C. Grauer, J. Yano, J. R. Long, P. Yang and C. J. Chang, J. Am. Chem. Soc., 2013, 135, 17699.

13 Y. B. Anothumakkool, R. Soni, S. N. Bhange and S. Kurungot, Energy Environ. Sci., 2015, 8, 1339.

14 L. R. Hou, C. Z. Yuan, D. K. Lia, L. Yang, L. F. Shen, F. Zhang and X. G. Zhang, Electrochim. Acta, 2011, 56, 7454.

15 M. H. Yu, W. Wang, C. Li, T. Zhai, X. H. Lu and Y. X. Tong, NPG Asia Mater., 2014, 6, 129.

16 W. T. Wei, L. W. Mi, Y. Gao, Z. Zheng, W. H. Chen and X. X. Guan, Chem. Mater., 2014, 26, 3418.

17 J. Pu, Z. H. Wang, K. L. Wu, N. Yua and E. H. Sheng, Phys. Chem. Chem. Phys., 2014, 26, 3418.

18 C. Yuan, L. Yang, L. Hou, J. Li, Y. Sun, X. Zhang, L. Shen, X. Lu, S. Xiong and X. W. Lou, Adv. Funct. Mater., 2012, 22, 2560 .

19 J. Li, S. Xiong, Y. Liu, Z. Ju and Y. Qian, ACS Appl. Mater. Interfaces, 2013, 5, 981.

20 T. Wang, B. Zhao, H. Jiang, H. Yang, K. Zhang, M. Yuen, X. Fu, R. Sun and C. Wong, J. Mater. Chem. A, 2015, 3, 23035.

21 J. Xiao, L. Wan, S. Yang, F. Xiao and S. Wang, Nano Lett., 2014, 14, 831.

22 B. You, N. Jiang, M. Sheng and Y. Sun, Chem. Commun., 2015, 51, 4252.

23 P. Justin and G. Rao, Int. J. Hydrogen Energy, 2010, 35, 9709.

24 S. Bao, C. Li, C. Guo and Y. Qiao, J. Power Sources, 2008, 180, 676.

25 N. Jiang, B. You, M. Sheng and Y. Sun, ChemCatChem, 2016, 8, 106.

26 B. You, N. Jiang, M. Sheng, M. W. Bhushan and Y. Sun, ACS Catal., 2016, 6, 714.

27 N. Jiang, B. You, M. Sheng and Y. Sun, Angew. Chem., Int. Ed., 2015, 54, 6251.

28 N. Jiang, L. Bogoev, M. Popova, S. Gul, J. Yano and Y. Sun, J. Mater. Chem. A, 2014, 2, 19407.

29 B. Anothumakkool and S. Kurungot, Chem. Commun., 2014, 50, 7188.

30 W. Xiao, H. Xia, J. Y. H. Fuh and L. Lu, J. Electrochem. Soc., 2009, 156, A627.

31 S. I. Kim, J. S. Lee, H. J. Ahn, H. K. Song and J. H. Jang, ACS Appl. Mater. Interfaces, 2013, 5, 1596.

32 L. Salvati, L. E. Makovsky, J. M. Stencel and F. R. Brown, J. Phys. Chem., 1981, 85, 3700.

$33 \mathrm{X} . \mathrm{Yu}, \mathrm{W}$. Sun and Y. Chu, New J. Chem., 2014, 38, 70.

34 H. Nesbitt, W. D. Legrand and G. M. Bancro, Phys. Chem. Miner., 2000, 27, 357. 
35 Z. Wang, P. Ling, H. Hu and S. Zhao, CrystEngComm, 2010, 38 H. Wan, J. Liu, Y. Ruan, L. Lv, L. Peng, X. Ji, L. Miao and 12, 1899. J. Jiang, ACS Appl. Mater. Interfaces, 2015, 7, 15840.

36 C. Chen, Z. Shi, Z. Yang and H. Chang, J. Power Sources, 2012, 39 H. Dai, Y. Zhou, Q. Sun, F. Lu and Z. W. Fu, Electrochim. Acta, 215, 43 . 2012, 76, 145.

37 K. S. Joya and X. Sala, Phys. Chem. Chem. Phys., 2015, 17, 21094. 